\title{
Effect of acute treatment with progesterone on the timing and synchrony of ovulation in Bos indicus heifers treated with a norgestomet implant for 17 days
}

\author{
J. Cavalieri ${ }^{1 *}$, J. E. Kinder ${ }^{3}$ and L. A. Fitzpatrick ${ }^{1,2, \dagger}$ \\ ${ }^{1}$ Australian Institute of Tropical Veterinary \& Animal Science, and ${ }^{2}$ Department of Physiology and \\ Pharmacology, James Cook University of North Queensland, Townsville, Q 4811, Australia; and \\ ${ }^{3}$ Department of Animal Science, University of Nebraska, Lincoln, NE 68583-0908, USA
}

\begin{abstract}
The aim of the present study was to develop a treatment protocol for the precise synchronization of oestrus that would avoid the development of persistent dominant ovarian follicles. Bos indicus heifers, in which oestrous cycles had been presynchronized, were allocated randomly, according to the day of their oestrous cycle, to one of five treatment groups. All heifers received a subcutaneous ear implant containing $3 \mathrm{mg}$ of norgestomet for 17 days starting on day $\mathrm{O}$ and an injection of an analogue of prostaglandin $\mathrm{F}_{2 \alpha}$ on days 0 and 4 . Heifers in group 1 (control group; $n=7$ ) received no other treatment, while heifers in groups $2(n=8), 3(n=7), 4(n=7)$, and $5(n=7)$ received a single progesterone-releasing controlled internal drug release device (CIDR) for $24 \mathrm{~h}$ on days 10, 12, 14 and 16 , respectively. Treatment with a single CIDR delayed the mean time of ovulation and the day of emergence of the ovulatory follicle in heifers treated on days 14 and 16 compared with control heifers $(P<0.05)$. There was less variation in the interval to ovulation in heifers treated on day 10 compared with other treated heifers $(P<0.05)$. The variation among heifers in the day of emergence of the ovulatory follicle and the age of the ovulatory follicle at ovulation was less for all groups treated with a CIDR than for the control group $(P<0.05)$. The duration of dominance and variation in the duration of dominance of the ovulatory follicle was less in heifers treated with a CIDR device on days 10 and 16 than for control heifers $(P<0.05)$. Mean age (days from emergence to ovulation) of the ovulatory follicle did not differ among treatment groups $(P>0.05)$. Concentrations of $\mathrm{LH}$ and oestradiol decreased coincident with increased concentrations of progesterone on the days of CIDR treatment in treated compared with control heifers $(P<0.02)$ but increased again after removal of the CIDR. A smaller proportion of follicles in the growing phase of follicular development at the time of CIDR treatment become atretic compared with follicles that had reached a plateau phase of follicular growth (14.3\% (1/7) versus $90.5 \%$ (19/21), respectively; $P<0.001$ ). It was concluded that acute treatment with progesterone can influence the growth pattern of ovarian follicular development. However, the effect varies with the stage of ovarian follicular development. Short term treatment with progesterone 7 days before the end of a 17 day period of norgestomet treatment resulted in precise synchrony of ovulation without the ovulation of a persistent dominant ovarian follicle.
\end{abstract}

\section{Introduction}

Progestogens are commonly used to synchronize oestrus in cattle by synchronizing the end of the progestational phase of the oestrous cycle (Odde, 1990; Wright and Malmo, 1992). However, while progestin-based systems of synchronizing oestrus are widely used and provide good control of the

*Present address: College of Veterinary Medicine, North Carolina State University, 4700 Hillsborough Street, Raleigh, NC 27606, USA.

${ }^{+}$Correspondence and reprint requests.

Revised manuscript received 27 August 1997. oestrous cycles of cattle, fertility at the synchronized oestrus has been variable (Miksch et al., 1978; Spitzer et al., 1978; Rentfrow et al., 1987; Brown et al., 1988; Favero et al., 1988; Odde, 1990). The reduction in fertility associated with the use of progestogens, in concentrations normally used to synchronize oestrus, has been attributed to abnormal oocyte development (Kinder et al., 1996).

When progestogens are administered in the absence of a functional corpus luteum at doses that are used commercially to synchronize oestrus, there is an increase in the frequency of release of $\mathrm{LH}$ from the anterior pituitary gland, the increase in 
peripheral concentrations of oestradiol is prolonged and ovarian follicles that are persistent develop, all of which are associated with a reduction in fertility at the synchronized oestrus (Savio et al., 1993; Cooperative Regional Research Project, 1996; Kinder et al., 1996). Treatments designed to prevent either the development of persistent follicles (Sanchez et al., 1993; Wehrman et al., 1993; Cooperative Regional Research Project, 1996) or induce recruitment of a new dominant follicle (Schmitt et al., 1996) have resulted in an improvement in fertility at the synchronized oestrus. Fertility is not compromised when the duration of dominance of the ovulatory follicle is limited to 4 days or fewer (Mihm et al., 1994). Effective methods to synchronize oestrus should, therefore, synchronize either ovarian follicular development, the time of individual luteal regression, or the end of a period of progestogen treatment. In addition, treatment should prevent prolonged and increased peripheral concentrations of oestradiol or an increase in the frequency of LH secretion and avoid prolonged periods of dominance of the ovulatory follicle.

Acute treatment with progesterone during a period of progestogen treatment results in atresia of persistent ovarian follicles and improves fertility at the synchronized oestrus in Bos taurus cattle (Anderson and Day, 1994). However, the effects of acute treatment with progesterone in Bos indicus heifers and the timing of such treatment relative to the end of the period of progestogen treatment on the synchrony of ovulation and its influence on ovarian follicular development have not been determined. The objective of the present study was to synchronize the time of ovulation in heifers without the development of a persistent dominant ovarian follicle and to determine the optimum time for short-term treatment with progesterone relative to the end of the period of progestogen treatment, that would result in the best synchrony of ovulation. Our aim was to develop a protocol for synchronizing behavioural oestrus that would result in precise synchrony of ovulation with normal fertility.

\section{Materials and Methods}

\section{Animals and treatments}

The study was conducted in spring. Serial ultrasound examination was used to confirm cyclic ovarian activity in 36, 2-year-old Bos indicus heifers (7/8 to 15/16 Brahman; mean weight \pm SEM: $347.4 \pm 7.2 \mathrm{~kg}$ ). The stage of the oestrous cycle was then synchronized with a s.c. silicone implant containing $3 \mathrm{mg}$ of norgestomet ( $17 \alpha$-acetoxy-11 $\beta$-methyl-19-norpreg-4en-3,20 dione; Crestar " , Intervet (Aust), Castle Hill, NSW), for 9 days and an i.m. injection of an analogue of prostaglandin $\mathrm{F}_{2 u}$ $\left(\mathrm{PGF}_{2 \mathrm{u}^{\prime}}, 15 \mathrm{mg}\right.$ Prosolvin ${ }^{\mathrm{Q})}$, Intervet (Aust), Castle Hill, NSW) on the day of implant insertion and removal. Ten days after the implants had been removed (day 0 ), heifers were allocated randomly, according to the day of their oestrous cycle (days 2 to $5, n=7$; day $6, n=9$; day $7, n=12$; and day $8, n=8$; respectively), to one of five treatment groups. All heifers received a single s.c. norgestomet ear implant ( $3 \mathrm{mg}$ ) on day 0 that was removed 17 days later and were injected with $15 \mathrm{mg}$ $\mathrm{PGF}_{2 a}$ analogue on days 0 and 4 to induce regression of corpora lutea. A preliminary study had confirmed that a $3 \mathrm{mg}$

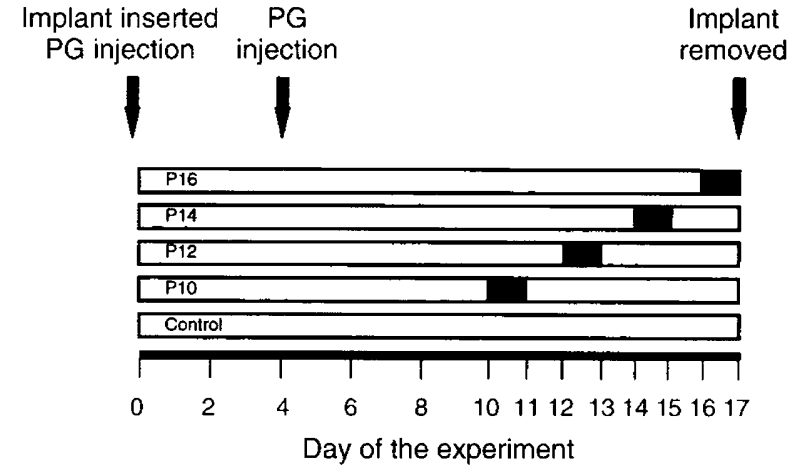

Fig. 1. Diagrammatic representation of treatment protocol. The open rectangles represent a single subcutaneous norgestomet implant inserted into heifers from days 0 to 17 . A progesterone-releasing controlled internal drug releasing device (shaded rectangles) was inserted on day 10 (P10), day 12 (P12), day 14 (P14) or day 16 (P16) and removed the following day. An injection of an analogue of prostaglandin $F_{2 *}$ (PG) was given to all heifers on days 0 and 4 . Implants were removed from all animals on day 17.

norgestomet ear implant would maintain Bos indicus heifers in anoestrus for at least 21 days (J. Cavalieri, unpublished). Heifers in the control group (control, $n=7$ ), received no other treatment. A progesterone-releasing controlled internal drug release (CIDR) device was inserted into the vagina of the remaining heifers for $24.2 \pm 0.06 \mathrm{~h}$ (mean \pm SEM) either on day 10 (P10, $n=8$ ), day 12 (P12, $n=7$ ), day 14 (P14, $n=7$ ) or day 16 (P16, $n=7$; Fig. 1).

\section{Ultrasonography}

The ovaries of heifers were examined using transrectal ultrasonography (Aloka 210 DX: 7.5 Mhz probe), by the same operator, on alternate days from days 0 to 10 , then once a day until signs of behavioural oestrus were detected. The ovaries of heifers were then examined every $6 \mathrm{~h}$ until ovulation was detected. The stage of growth of ovarian follicles at the time of treatment with progesterone was categorized as either in the growing phase (when a follicle was $5-9 \mathrm{~mm}$ in diameter and still increasing in size) or as in the plateau phase (when there had been no increase in the size of the dominant follicle for 2 consecutive days or the dominant follicle was $\geq 10 \mathrm{~mm}$ in diameter. The mean maximum diameter of dominant follicles in Bos indicus heifers has been reported as $10 \mathrm{~mm}$ (Rhodes et al., 1994). A new wave of follicular development always began before regression of the dominant follicle had been detected.

The day of emergence of the ovulatory follicle was defined, retrospectively, as the day on which the ovulatory follicle was first detected at a size of $>5 \mathrm{~mm}$ in diameter. The age of the ovulatory follicle was defined as the time interval (days) between the day of emergence of the ovulatory follicle and the time of ovulation. The first day of dominance of the ovulatory follicle was defined using the criteria described by Mihm et al. (1994), that is, the first day that (1) subordinate follicles stop increasing in diameter, (2) the ovulatory follicle was $\geq 8.5 \mathrm{~mm}$, or (3) the diameter of the ovulatory follicle was $>2 \mathrm{~mm}$ larger than any subordinate follicles (not essential). The duration of 
dominance of the ovulatory follicle (days) was defined as the interval between the first day of dominance and the day of ovulation minus one day.

\section{Blood sampling and radioimmunoassays}

Concentrations of progesterone in plasma were measured in unextracted plasma samples by radioimmunoassay using a modification of the Danazol method (McGinley and Casey, 1979) described by Jolly (1992). The sensitivity of the assay $\left(90 \%\right.$ zero-binding) was $0.03 \mathrm{ng} \mathrm{ml}^{-1}$ and intra- and interassay coefficients of variation at the approximate mid-point of the standard curve $\left(1.0 \mathrm{ng} \mathrm{ml}^{-1}\right)$ were $13.1 \%$ and $16.1 \%$, respectively.

Concentrations of plasma LH were measured by doubleantibody radioimmunoassay, using a modification of the method described by Niswender et al. (1969) that has been validated in our laboratory (Rhodes et al., 1995a). Purified bovine LH (USDA-bLH-B-6, AFP-11743-B) was provided by D. Bolt (USDA Animal Hormone Program, Beltsville, MD, USA). The antiserum used was NIDDK-anti-oLH-1 (AFP-192279), which was supplied by NIDDK, Bethesda, MD. The sensitivity of this assay ( $90 \%$ of zero-binding) was $0.2 \mathrm{ng} \mathrm{ml}^{-1}$. Intra- and interassay coefficients of variation were $13.5 \%$ and $16.5 \%$, respectively.

Concentrations of plasma oestradiol were determined by radioimmunoassay in the Physiology Laboratory of the University of Nebraska, using antiserum to oestradiol (lot no. 022367) provided by N. R. Mason (Lilly Research Laboratories, Indianapolis, IN) and oestradiol, (Sigma Chemical Co., St. Louis, $\mathrm{MO})$ as standard. The procedure for this assay has been reported and validated by Kojima et al. (1992). The sensitivity of this assay $\left(90 \%\right.$ of zero binding) was $0.07 \mathrm{pg} \mathrm{m}^{-1}$. Intraand interassay coefficients of variation were $13.4 \%$ and $16.4 \%$, respectively.

\section{Statistical analyses}

Initial data analysis suggested highly variable non-normal distribution of data. Therefore, bootstrap estimates of location (mean) and spread (SD) were used for the variables, age of follicle (number of days between emergence and ovulation of follicle), day of emergence and duration of dominance of the ovulatory follicle, and time elapsing from implant removal to ovulation. The bootstrap is a recently developed technique for making certain types of statistical inferences (Efron and Tibshirani, 1993). Bias corrected and accelerated estimates were used to calculate both estimates and confidence intervals (CIs; Efron and Tibshirani, 1993) using the bootstrap library provided in Statlab (Splus, StatSci Division, MathSoft Inc., Seattle, Washington, 1995). Splus 3.3 for Windows was used to run the library.

For the purposes of comparisons of means and SD among treatment groups, the $90 \% \mathrm{Cls}$ can be used as follows. Non-overlapping $90 \%$ CIs represent a significant difference at approximately the $1 \%$ level of significance. This makes no allowance for multiple comparisons and is hence equivalent to performing multiple $t$ tests. Multiple comparisons using the Bonferoni method were catered for by increasing the level of
$1 \%$ by approximately the number of tests used. Thus, if each group is to be compared with the control (that is, four comparisons), then the level of significance would be marginally less than $5 \%$.

Endocrine concentrations were log transformed (base 10) to achieve constant variance over the sampling period. Changes in plasma concentrations of progesterone, $\mathrm{LH}$, and oestradiol over time were analysed for effects of group, day and group-by-day interaction using multivariate repeated measures analysis of variance (Lindsey, 1993). If the group effect or the day-bygroup effect was significant $(P<0.05)$, means of individual treatment groups were compared with the control group using Student's $t$ test. The proportion of either growing $(5-9 \mathrm{~mm}$ in diameter) or plateau phase ovarian follicles, present at the start of treatment with progesterone, that became atretic and did not ovulate was compared using a two-tailed Fisher's exact test (Bradley, 1968).

\section{Results}

One animal in the P16 group failed to ovulate within 10 days of implant removal and data from this animal were excluded from analyses pertaining to follicular growth, but were included in the analyses of endocrine changes.

\section{Endocrine changes}

For the purpose of statistical analysis, changes in concentrations of hormones over time were divided into two time periods, days $0-10$ and days 10-18. Changes in concentrations of oestradiol, $\mathrm{LH}$ and progesterone for each treatment group from days 0 to 18 are shown (Fig. 2).

Days 0 to 10 . There was a significant effect of day $(P<0.001)$, but no group $(P>0.270)$, or group-by-day interaction $(P>0.280)$ on plasma concentrations of progesterone, oestradiol and LH between days $0-10$. Mean ( \pm SEM) concentrations of progesterone declined $(P<0.001)$ from day 0 $\left(3.023 \pm 0.267 \mathrm{ng} \mathrm{ml}^{-1}\right)$ to day $2\left(0.525 \pm 0.065 \mathrm{ng} \mathrm{ml}^{-1}\right)$ and remained at basal concentrations in all groups until day 10 . Concentrations of LH initially increased $(P<0.001)$ from day 0 to day 2 , decreased $(P<0.001)$ from day 2 to day 6 and then increased $(P<0.001)$ again by day 10 . Concentrations of oestradiol increased $(P<0.001)$ from day 0 to day 10 .

Days 10 to 18 . A significant group-by-day interaction $(P<0.001)$ was detected for plasma concentrations of progesterone between days 10 and 18 . Insertion of a CIDR device for $24 \mathrm{~h}$ resulted in increased concentrations of progesterone in the treated animals compared with the control animals during the period of CIDR treatment $(P<0.001)$. Mean concentrations of progesterone in the plasma of treated heifers at the time of removal of the CIDR ranged between 4.196 and $4.879 \mathrm{ng}$ $\mathrm{ml}^{-1}$, while mean concentrations of progesterone in plasma of the control heifers were $<0.250 \mathrm{ng} \mathrm{ml}^{-\mathrm{I}}$ on each of the days CIDRs were in place. Concentrations of progesterone decreased to mean basal values of $<0.7 \mathrm{ng} \mathrm{ml}^{-1}$ in each of the treated groups $24 \mathrm{~h}$ after removal of the CIDR. Luteal 

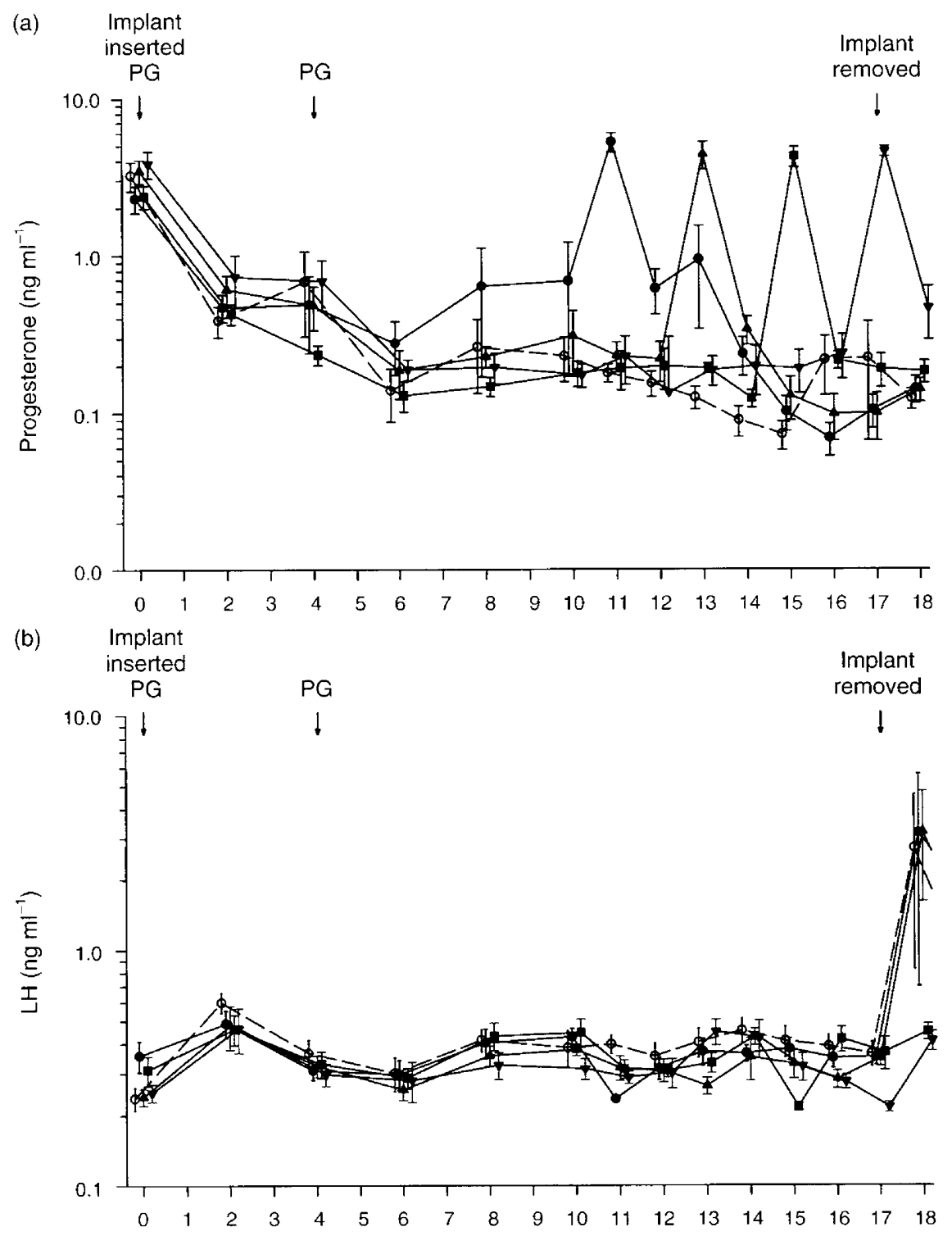

(c) Implant $\quad$ implant

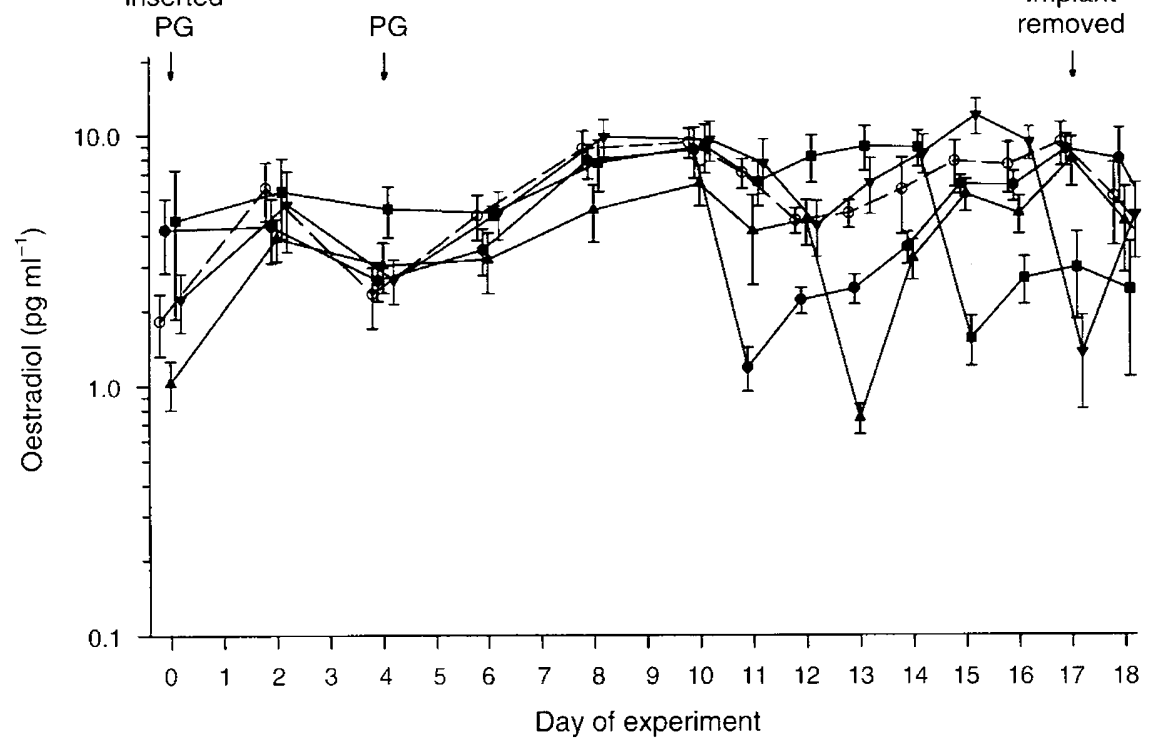


regression did not occur in one heifer in group P10 until day 14 and this contributed to the group effect $(P=0.033)$ detected between days 10 and 18 .

A group-by-day interaction $(P<0.001)$ was detected for concentrations of LH between days 10 and 18. At the time of removal of the CIDR, mean concentrations of plasma $\mathrm{LH}$ in each group of treated heifers were lower than concentrations of LH in control heifers (control versus P10, P14, P16, P<0.01; control versus $P 12, P=0.02$ ). Mean concentrations of $\mathrm{LH}$ in heifers in groups $2,3,4$ and 5 at the time of CIDR removal were $53,41,61$ and $45 \%$, respectively for each group, lower than concentrations of LH in the control heifers. Mean concentrations of LH in animals in groups P10, P12 and P14 increased $24 \mathrm{~h}$ after removal of the CIDR and were not different from concentrations in the control heifers $(P>0.150)$. Although concentrations of LH in heifers in group P16 increased from day 17 to day 18 , LH concentrations in these heifers on day 18 was still significantly lower $(P=0.040)$ than corresponding LH concentrations in the control heifers, due to the recording of a preovulatory LH surge in some of the control animals.

A group-by-day interaction $(P<0.001)$ was detected for concentrations of oestradiol between days 10 and 18. Mean circulating concentrations of oestradiol at the time of CIDR removal had decreased by $85 \%, 84 \%, 82 \%, 91 \%$, respectively, for groups P10, P12, P14 and P16, when compared with the time of CIDR insertion. Concentrations of oestradiol were lower in all treatment groups at the time of CIDR removal than the respective concentrations of oestradiol in the control heifers on that day $(P<0.001)$. Concentrations of oestradiol in the plasma of treated heifers increased after removal of CIDR devices. The times required for mean concentrations of oestradiol to increase, after progesterone withdrawal, to within the $95 \%$ confidence interval of the mean concentration of oestradiol for the 2 days before treatment, were 5, 3, 4 and 6 days for groups P10, P12, P14 and P16, respectively.

\section{Ovarian follicular development}

During the 17 day period of norgestomet treatment, heifers from the control and P10 groups had two or three waves of follicular development, while heifers in groups P12-P16 had two, three or four waves of follicular development. Treatment with a CIDR device for $24 \mathrm{~h}$ delayed ovulation and the day of emergence of the ovulatory follicle only in animals treated within 3 days of implant removal (groups P14 and P16) $(P<0.05$; Fig. 3 ). A greater variability in the time of ovulation was evident in the P12 and P16 animals compared with the control animals and in the P16 animals compared with P10, P12 and P14 heifers. Variability in the time of ovulation between the P10, P14 groups and the control group was similar $(P>0.05$; Fig. 3). The day of emergence of the ovulatory follicle varied less among heifers in each of the four treatment groups compared with heifers in the control group $(P<0.05$;
Fig. 3). There was a trend towards a reduction in the mean age of the ovulatory follicle in the treated animals compared with control animals, although the difference was never significant $(P>0.0$; Fig. 4). The age of the ovulatory follicle, however, varied more among the control animals than among any of the animals in the other four treatment groups $(P<0.05$, Fig. 4). The mean duration of dominance (days) of the ovulatory follicle was less in animals treated on day 10 and day 16, but also varied less in animals treated on days 10, 14 and 16 compared with the control animals $(P<0.05$, Fig. 4). None of the ovarian follicles observed in animals in the P10 group at the beginning of treatment with progesterone could be retrospectively identified as the ovulatory follicle. However, in $57.1 \%$ $(4 / 7), 28.6 \%(2 / 7)$ and $33.3 \%(2 / 6)$ of animals in groups 3,4 and 5 , respectively, the ovulatory follicle could retrospectively be identified as being present in the ovary at the time when treatment with progesterone began. The growth of the ovulatory follicle for each animal in each treatment group is shown (Fig. 5). The probability of causing atresia of ovarian follicles in animals treated with progesterone differed according to stage of follicular growth at the time of treatment with progesterone. A smaller proportion of follicles that were in the growing phase (5-9 $\mathrm{mm}$ in diameter) of follicular development became atretic as a result of treatment with progesterone when compared with follicles that had reached the plateau phase of follicular growth (14.3\% (1/7) versus $90.5 \%$ (19/21), respectively; $P<0.001$ ).

\section{Discussion}

The results of the present study are in agreement with the findings of others who have reported that acute treatment with progesterone can induce atresia of dominant ovarian follicles and the emergence of a new wave of follicular development (Rajamahendran and Manikkam, 1994; Anderson and Day, 1994). Data from the present study, however, indicate that the time when progesterone treatment is administered, relative to the end of a period of norgestomet treatment, will affect the timing and synchrony of ovulation. Treatment with progesterone, 7 days before (day 10) the removal of norgestomet implants, provided the best balance between achieving a precise time of ovulation and avoiding the ovulation of an aged oocyte. Mihm et al. (1994) demonstrated that a sequential reduction in pregnancy rates occurred as the duration of dominance of the largest follicle increased from 4 days to 8 days in heifers in which oestrus was synchronized with norgestomet, while no pregnancies occurred in heifers in which the duration of follicular dominance exceeded 10 days (Mihm et al., 1994). In studies in which small doses of progestins were used, the extension of periods of follicular dominance resulted in a reduction in fertility (Savio et al., 1993; Stock and Fortune, 1993; Cooperative Regional Research Project, 1996). Acute treatment with progesterone 7 days before ending

Fig. 2. Profiles of mean ( \pm SEM) concentrations of (a) progesterone, (b) LH and (c) oestradiol in heifers treated with a norgestomet implant for 17 days (starting on day 0 ) and an injection of an analogue of prostaglandin $\mathrm{F}_{2 u}(\mathrm{PG})$ on days 0 and 4 . Heifers in the control group ( $\mathrm{C}$ ) received no other treatment. Heifers in groups P10 $(\mathbf{O}), \operatorname{P12}(\mathbf{v})$, P14 $(\triangle)$ and P16 $(\nabla)$ were treated with a progesterone-releasing controlled internal drug releasing device for $24 \mathrm{~h}$ starting on days $10,12,14$ and 16 , respectively. 

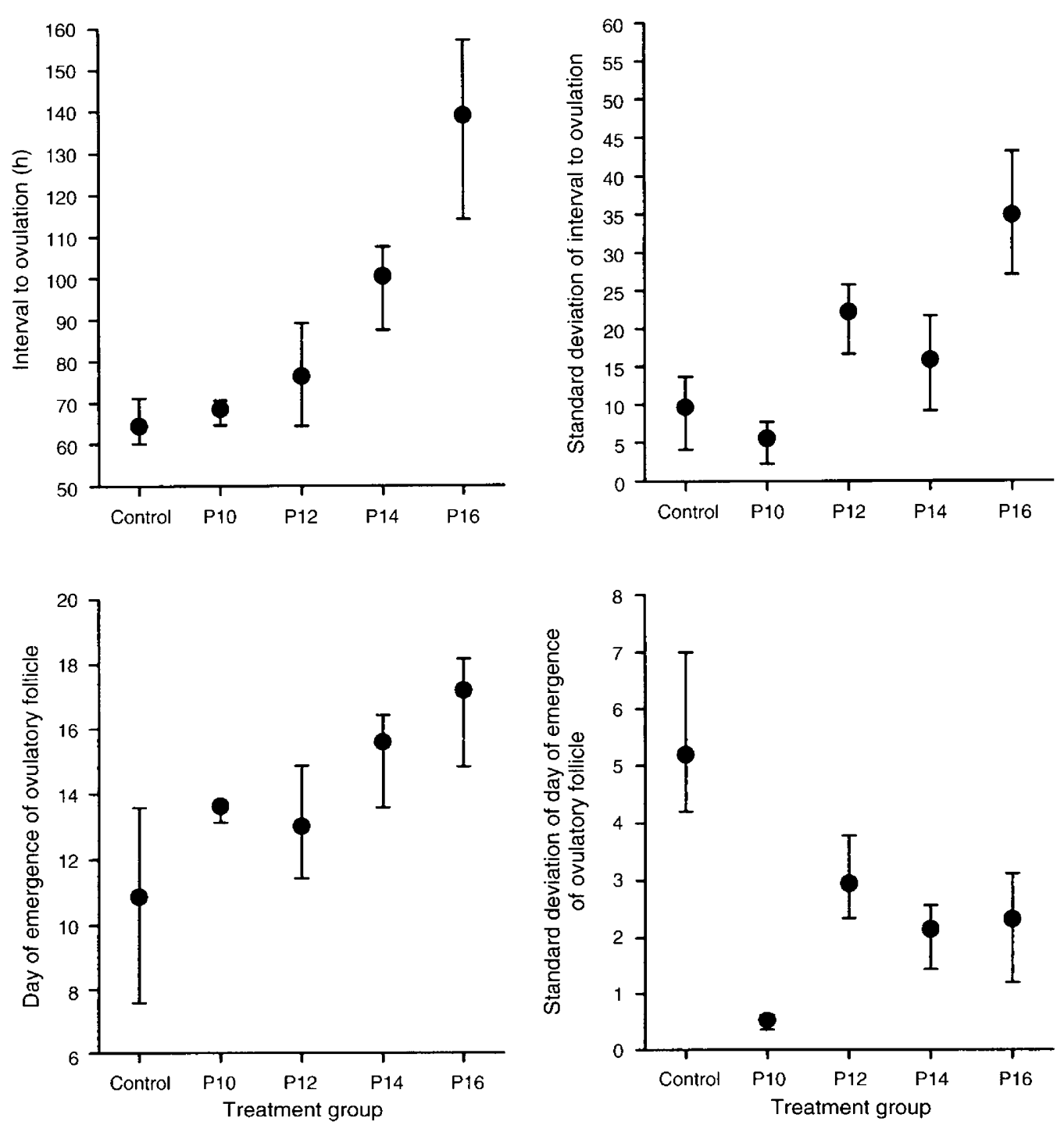

Fig. 3. Bootstrap estimates of location (mean) and spread $(\mathrm{SD})$ ( $\pm 90 \%$ confidence interval) of the time interval from the end of norgestomet treatment to ovulation and day of emergence of the ovulatory follicle. Non-overlapping $90 \%$ confidence intervals differ $(P<0.05)$. Heifers were treated with a norgestomet implant for 17 days (starting on day 0 ) and an injection of an analogue of prostaglandin $F_{2 u}$ on days 0 and 4 . Heifers in the control group received no other treatment. Heifers in groups P10, P12, P14 and P16 were treated with a progesterone-releasing controlled internal drug releasing device for $24 \mathrm{~h}$ starting on days 10, 12, 14 and 16, respectively.

norgestomet treatment offers the advantage of producing precise ovulation synchrony while at the same time preventing ovulation of persistent dominant follicles and would, therefore, be expected to result in normal fertility.

Variability of synchrony of ovulation occurred in Bos indicus cows when they were treated with a CIDR device for 10 days (day 0 to day 10) and then treated with an additional CIDR device for $48 \mathrm{~h}$ from day 8 to day 10 (Cavalieri et al., 1997). It was concluded in that study that variation among animals in the timing of emergence of ovulatory follicles, follicular growth rates and maturation times for ovarian follicles after the administration of the atretogenic treatment could have contributed to the variability of ovulation synchrony that was observed. In addition, a longer period of progestin treatment after the application of an atretogenic treatment might be needed to improve the synchrony of ovulation. The results of the study reported here confirm that acute treatment with progesterone at the end of a period of progestogen treatment does result in a variable pattern of ovulation synchrony and that increasing the time interval between progesterone treatment and extending the period of progestogen treatment to 7 days improves ovulation synchrony.

Two to three waves of ovarian follicular development were detected in the control animals even though regression of corpora lutea was induced early during the period of norgestomet treatment. This finding contrasts with previous studies in which the use of single s.c. norgestomet implants in Bos taurus cattle, in the absence of a corpus luteum, increased 

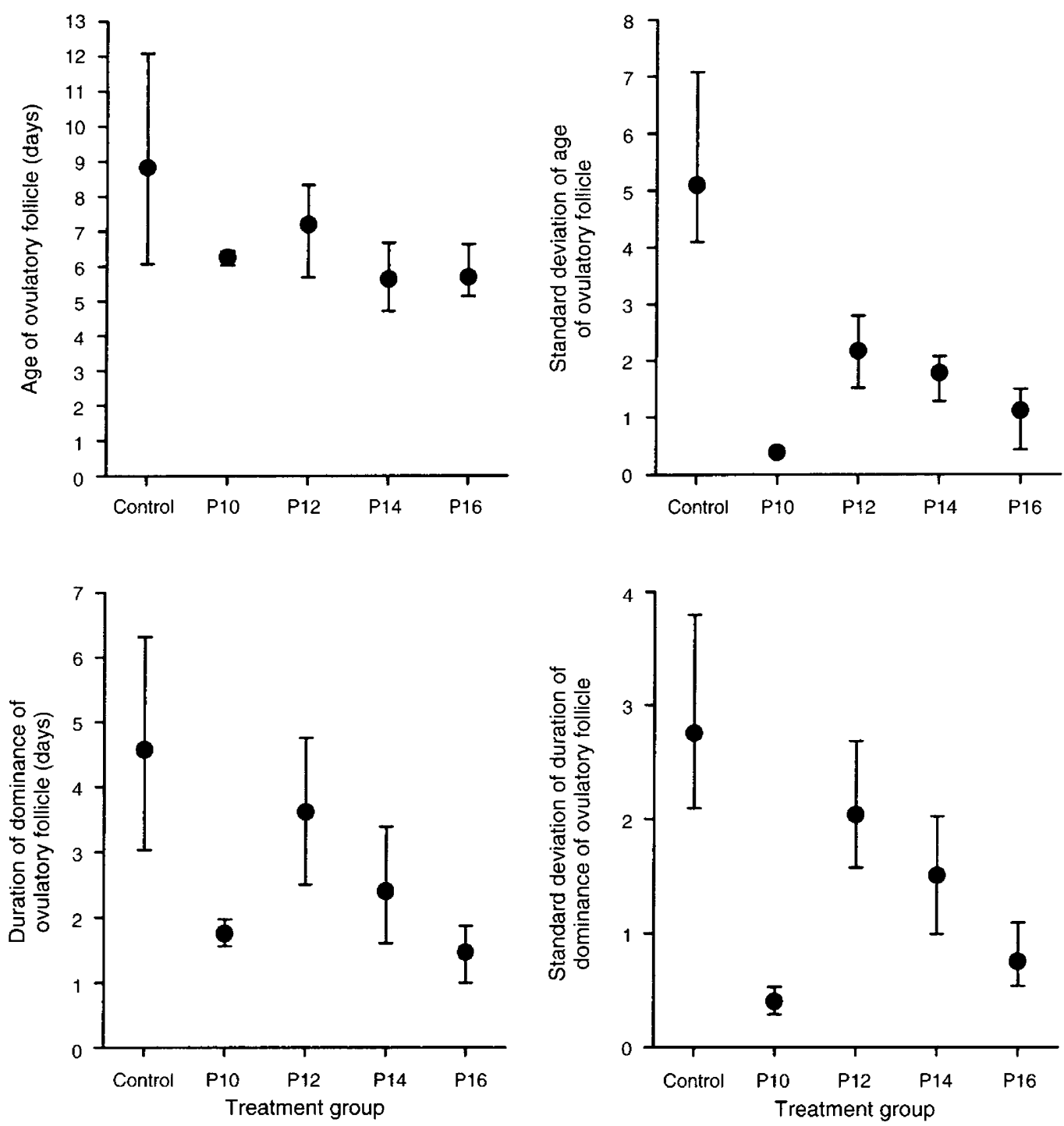

Fig. 4. Bootstrap estimates of location (mean) and spread (SD) ( $\pm 90 \%$ confidence interval) of the age and duration of dominance of the ovulatory follicle. Non-overlapping $90 \%$ confidence intervals differ $(P<0.05)$. Heifers were treated with a norgestomet implant for 17 days (starting on day 0 ) and an injection of an analogue of prostaglandin $F_{2 a}$ on days 0 and 4 . Heifers in the control group received no other treatment. Heifers in groups P10, P12, P14 and P16 were treated with a progesterone-releasing controlled internal drug releasing device for $24 \mathrm{~h}$ starting on days $10,12,14$ and 16 , respectively.

LH pulse frequency and prolonged the maintenance of dominant ovarian follicles (Savio et al., 1993; Taylor et al., 1993, 1994). In cows undergoing normal oestrous cycles, the presence of basal concentrations of gonadotrophins during the luteal phase of the oestrous cycle results in regular waves of ovarian follicular development (Fortune, 1993). It would appear that concentrations of circulating norgestomet were sufficient, in some of the heifers in the control group in the present study, to allow the continued periodic emergence of follicular waves during the implantation period. Differences in genotype, sensitivity to circulating concentrations of norgestomet, bodyweight or the timing of insertion of the norgestomet implants might explain why dominant follicles were not maintained for the duration of progestogen treatment in the control heifers in the present study. Greater fertility and differing patterns of release of norgestomet have been observed when norgestomet was administered in silicone as opposed to hydron implants (Kesler et al., 1995), which might indicate that persistent dominant follicles are less common when silicone implants are used to administer norgestomet. Acute treatment with progesterone offers an additional means of reducing variability in the growth pattern of the ovulatory follicle in heifers implanted with a norgestomet implant.

The reduction in observed variability in the growth pattern of the ovulatory follicle in most heifers treated with progesterone was due to treatment rendering most follicles anovulatory. Acute treatment with progesterone, however, was more effective in follicles that had reached a plateau phase in growth at the time of treatment compared with follicles still in the growing phase. This finding indicates that the development 


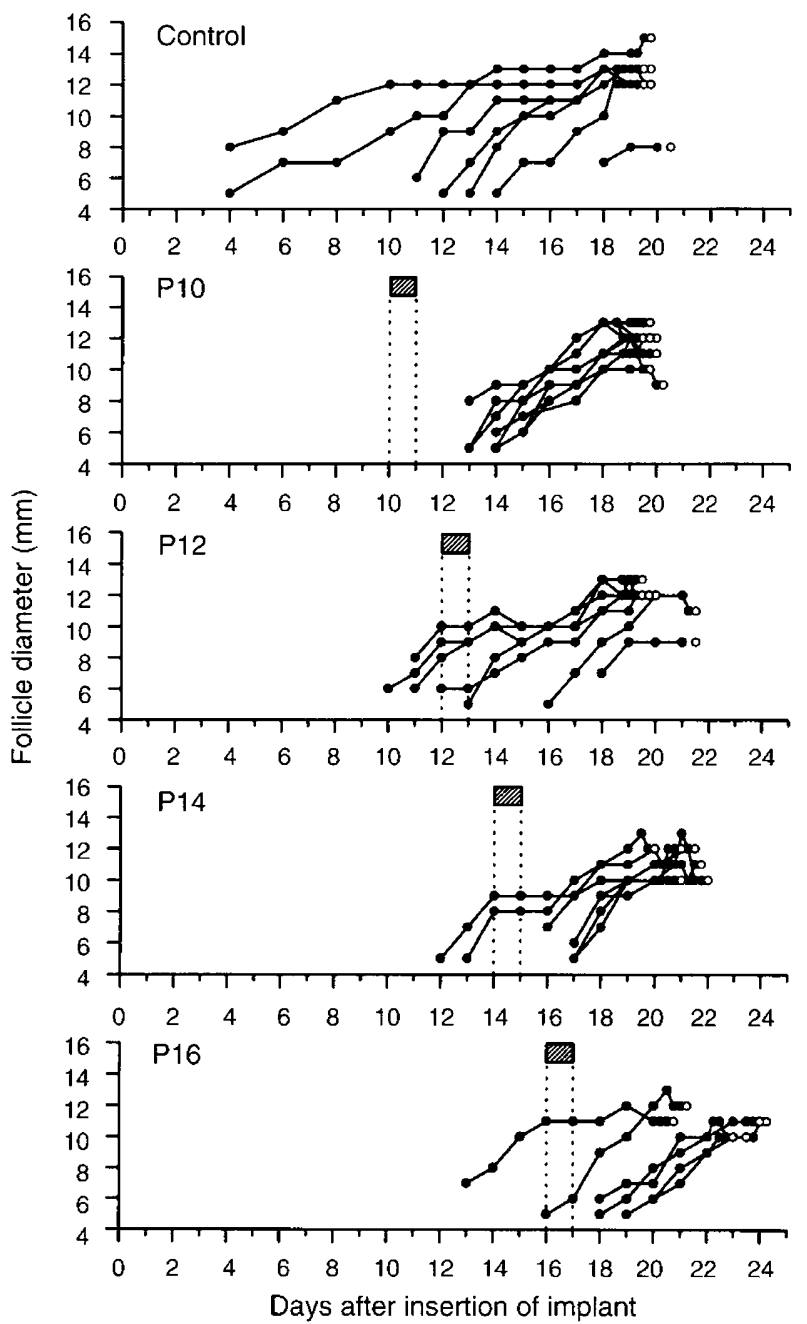

Fig. 5. Pattern of emergence and growth of the ovulatory follicle for each heifer in each treatment group, up until ovulation was detected, as recorded by transrectal ultrasonography. ( $\square \Delta$ ) indicates the presence of a progesterone-releasing controlled internal drug releasing device; (O) indicates time ovulation was detected. Heifers were treated with a norgestomet implant for 17 days (starting on day 0 ) and an injection of an analogue of prostaglandin $\mathrm{F}_{2 u}$ on days 0 and 4 . Heifers in the control group received no other treatment. Heifers in groups P10, P12, P14 and P16 were treated with a progesterone-releasing controlled internal drug releasing device for $24 \mathrm{~h}$ starting on days 10, 12, 14 and 16 , respectively.

and maintenance of dominant follicles are less likely to be arrested by exogenous treatment with progesterone during the growing stages of ovarian follicular growth. Differences in the sensitivity of ovarian follicles to atresia resulting from treatment with progesterone may relate to the number of LH receptors present in a follicle and to the dependence of a follicle on LH for continued viability. Dominant, gonadotrophindependent, ovarian follicles are thought to be able to survive in an environment of reducing concentrations of FSH because of their increased sensitivity to FSH. LH receptors in granulosa cells, therefore, are transferring their gonadotrophic requirement from FSH to LH (Scaramuzzi et al., 1993; Campbell et al., 1995). This change, however, makes dominant follicles critically dependent on LH for survival, and so the reduction in mean LH concentrations observed in the present study, coincident with progesterone treatment, may have deprived dominant follicles of sufficient aromatisable substrate and thereby, initiated atresia. During the early stages of growth, those follicles, that are less dependent on LH for their survival, would be less susceptible to acute treatments with progesterone which reduce the frequency of pulsatile $\mathrm{LH}$ secretion (Rajamahendran and Manikkam, 1994). Therefore, in cattle, in which oestrus has been synchronized with progestogens, acute treatment with progesterone is more likely to render anovulatory those follicles that had achieved a functional state of dominance at the time of treatment, as these follicles would be more susceptible to a reduction in LH secretion. This would explain why in the study described here, actively growing follicles were less susceptible to the atretogenic effects of treatment with progesterone.

Atresia of all dominant or growing follicles that were observed in the ovaries at the time of treatment with progesterone was achieved in the P10 heifers as a result of treatment. This atresia resulted in a more synchronous emergence of the ovulatory follicle in this group and may have contributed to the more precise timing of ovulation observed compared with heifers in the other progesterone-treated groups. One step towards improving ovulation synchrony might be to improve the efficiency of atretogenic treatments. The results of the present study suggest that this could be achieved by inducing the development of a persistent dominant follicle, before administration of the atretogenic treatment, by treatment with progesterone at concentrations that are lower than usually occur during a normal luteal phase of an oestrous cycle $(<3 \mathrm{ng}$ $\mathrm{ml}^{-1}$ ), or by using concentrations of progestogens that are used commercially to synchronize oestrus in the absence of a corpus luteum (Sirois and Fortune, 1990; Adams et al., 1992; Savio et al., 1993; Stock and Fortune, 1993; Cooperative Regional Research Project, 1996).

The reduction in mean concentrations of LH in plasma $24 \mathrm{~h}$ after the beginning of treatment with progesterone is in agreement with previous findings in both Bos indicus cows (Cavalieri et al., 1997), and Bos taurus heifers (Burke and Macmillan, 1995; Bergfeld et al., 1996) treated with exogenous progesterone. The decline in mean concentrations of oestradiol during the period of progesterone treatment and subsequent increase after the removal of CIDR devices is probably due to changes in both the secretory pattern of $\mathrm{LH}$ and the disruption of the functional integrity of dominant follicles by progesterone treatment. Production of oestradiol is related to the frequency of LH pulses (Walters et al., 1984; Rhodes et al., 1995a). Thus, the reduction in mean concentrations of oestradiol is consistent with the reduction in mean concentrations of LH in the present study.

The increase in mean concentrations of $\mathrm{LH}$ in each group of heifers treated with progesterone after treatment had stopped was probably due to a reduction in progesterone-mediated negative feedback on LH secretion after the removal of the CIDR devices; progesterone is known to affect the pulsatile secretion of LH in a dose-dependent manner (Ireland and Roche, 1982; Roberson et al., 1989; Bergfeld et al., 1995, 1996). Mean concentrations of oestradiol, however, increased at a variable rate after the removal of CIDR devices with 
concentrations of oestradiol taking between 3 and 6 days to increase to pretreatment values.

Other studies have shown that atresia of dominant follicles is associated with a reduced capacity for secretion of oestradiol (Sunderland et al., 1994; Rhodes et al., 1995b). Thus, our results are consistent with progesterone treatment causing a loss of functional dominance of ovarian follicles. The more rapid increase in oestradiol concentrations in, for example, the heifers in the P12 group was probably due to a smaller proportion of follicles being rendered anovulatory by the treatment. $\mathrm{LH}$ concentrations were reduced only for the first $24 \mathrm{~h}$ of CIDR treatment, yet atresia of dominant follicles was still observed in most heifers treated with progesterone. This result supports the contention of Anderson and Day (1994) that only a transient reduction in LH secretion is needed to induce atresia of dominant follicles. Whether there is a critical threshold for circulating concentrations of progesterone, or a critical duration for the presence of physiological concentrations of progesterone that is necessary before a dominant follicle is rendered anovulatory remains to be determined. In addition, whether the dose and duration of progesterone that is necessary to cause atresia varies with the stage of follicular development also requires further investigation.

In conclusion, the findings reported here indicate that acute treatment with progesterone during a period of norgestomet treatment can reduce variation in the day of emergence, and the age and duration of a dominant follicle, and, therefore, could be used to improve fertility in animals in which the stage of oestrous cycles has been synchronized with progestogens. However, extensive field trials are needed to test the potential of this treatment protocol. The timing and synchrony of ovulation were influenced by the timing of acute treatment with progesterone relative to the end of progestogen treatment. Treatment with progesterone, 7 days before the ending of a 17 day period of norgestomet treatment, resulted in precise synchrony of ovulation and prevented the ovulation of a persistent dominant ovarian follicle. Susceptibility of ovarian follicles to atresia during exogenous treatment with progesterone also varies with stage of follicular development and this will need to be considered when designing treatments to synchronize oestrus.

The authors thank J. Britt for critical review of this manuscript, D. Bolt (USDA Animal Hormone Program) and the NIDDK for the provision of materials for the LH assays, N.R. Mason for providing the antiserum to oestradiol and Intervet (Aust) for providing Crestar ${ }^{12}$ and Prosolvin ${ }^{\mathrm{R}}$. The assistance of J. Morrison and C. Toombs with hormone assays and the technical assistance of J. Palpratt, P. Finlay and A. Finlay with management of experimental animals is gratefully acknowledged, as is the assistance of G. De'ath with the statistical analyses. Animals were kindly provided by the James Cook University Tropical Veterinary Research Station, Fletcherview, G. Fordyce of the Department of Primary Industries Experimental Field Station, Swans Lagoon and T. Mann of Hillgrove Station. Funding was provided by Intervet (Aust), James Cook University Meritorius Research Grant, and the Meat Research Corporation.

\section{References}

Adams GP, Matteri RL and Ginther OJ (1992) Effect of progesterone on ovarian follicles, emergence of follicular waves and circulating follicle-stimulating hormone in heifers Journal of Reproduction and Fertility 96 627-640
Anderson LH and Day ML (1994) Acute progesterone administration regresses persistent dominant follicles and improves fertility of cattle in which estrus was synchronized with melengestrol acetate Journal of Animal Science $\mathbf{7 2}$ 2955-2961

Bergfeld EG, Kojima FN, Wehrman ME, Cupp AS, Mariscal V, Sanchez T, Kittok R, Garcia-Winder M and Kinder JE (1995) Frequency of luteinizing hormone pulses and circulating 17\%-estradiol in cows is related to concentrations of progesterone in circulation when the progesterone comes from either an endogenous or exogenous source Animal Reproduction Science 37 257-265

Bergfeld EGM, Kojima AS, Cupp ME, Wehrman ME, Peters KE, Mariscal V, Sanchez T and Kinder JE (1996) Changing dose of progesterone results in sudden changes in frequency of luteinizing hormone pulses and secretion of 17ß-estradiol in bovine females Biology of Reproduction 54 546-553

Bradley JV (1968) Distribution-Free Statistical Tests. Prentice-Hall. Englewood Cliffs, NJ

Brown LN, Odde KG, King ME, LeFever DG and Neubauer CJ (1988) Comparison of melengesterol acetate-prostaglandin $\mathrm{F}_{2 \mu}$ to syncro-mate $\mathrm{B}$ for estrus synchronisation in beef heifers Theriogenology 30 1-12

Burke CR and Macmillan KL (1995) The effects of intravaginal administration of progesterone and oestradiol benzoate on circulating $\mathrm{LH}$ in ovariectomised cows Proceedings of the Australian Society of Reproductive Biology 2738

Campbell BK, Scaramuzzi RJ and Webb R (1995) Control of antral follicle development and selection in sheep and cattle Journal of Reproduction and Fertility Supplement $49335-350$

Cavalieri J, Kinder JE, De'ath G and Fitzpatrick LA (1997) Effect of $48 \mathrm{~h}$ treatment with $17 \beta$-oestradiol or progesterone on follicular wave emergence and synchrony of ovulation in Bos indicus cows when administered at the end of a period of progesterone treatment Animal Reproduction Science 46 187-201

Cooperative Regional Research Project, NE-161 (1996) Relationship of fertility to patterns of ovarian follicular development and associated hormonal profiles in dairy cows and heifers Journal of Animal Science 74 1943-1952

Efron B and Tibshirani RJ (1993) An Introduction to the Bootstrap. Chapman and Hall, New York

Favero RJ, Faulkner DB and Kesler DJ (1988) Estrous synchronization in beef females with Syncro-Mate-B: efficacy and factors that restrict optimal pregnancy rates Theriogenology 29245

Fortune JE (1993) Follicular dynamics during the bovine estrous cycle: a limiting factor in improvement of fertility? Animal Reproduction Science 33 $111-125$

Ireland JJ and Roche JF (1982) Effect of progesterone on basal LH and episodic LH and FSH secretion in heifers Journal of Reproduction and Fertility 64 295-302

Jolly PJ (1992) Physiological and Nutritional Aspects of Postpartum Acyclicity in Bos indicus cows. PhD Thesis, James Cook University of North Queensland, Townsville, Australia

Kesler DJ, Favero RJ and Toxel TR (1995) A comparison of hydron and silicone implants in the bovine norgestomet and estradiol valerate estrus synchronization procedure Drug Development and Industrial Pharmacy 21 475-485

Kinder JE, Kojima FN, Bergfeld EGM, Wehrman ME and Peters KE (1996) Progestin and estrogen regulation of pulsatile LH release and development of persistent ovarian follicles in cattle Journal of Animal Science 74 1424-1440

Kojima N, Stumpf TT, Cupp AS, Werth LA, Roberson MS, Wolfe MW, Kittok RJ and Kinder JE (1992) Exogenous progesterone and progestins as used in estrous synchrony regimens do not mimic the corpus luteum in regulation of luteinizing hormone and $17 \beta$-estradiol in circulation of cows Biology of Reproduction 47 1009-1017

Lindsey JK (1993) Models for Repeated Measurements. Clarendon Press, Oxford McGinley R and Casey JH (1979) Analysis of progesterone in unextracted serum: a method using danazol [17 $\alpha$-pregn-4-en-20-yno(2,3-d) isoxazol-17ol], a blocker of steroid binding to proteins Steroids 33 127-I38

Mihm M, Baguisi A, Boland MP and Roche JF (1994) Association between the duration of dominance of the ovulatory follicle and pregnancy rate in beef heifers Journal of Reproduction and Fertility 102 123-130

Miksch ED, LeFever D G, Mukembo G, Spitzer JC and Wiltbank JN (1978) Synchronization of estrus in beef cattle. Il. Effect of an injection of norgestomet and an estrogen in conjunction with a norgestomet implant in heifers and cows Theriogenology 10 201-221

Niswender GD, Reichert LE Jr, Midgley AR Jr and Nalbandov AV (1969) Radioimmunoassay for bovine and ovine luteinising hormone Endocrinology 84 1166-1173 
Odde KG (1990) A review of synchronization of estrus in postpartum cattle Joumal of Animal Science 68 817-830

Rajamahendran R and Manikkam M (1994) Effects of exogenous steroid hormones on the dominant follicle maintained by a Norgestomet implant in heifers Canadian Journal of Animal Science 74 457-464

Rentfrow KR, Randel RD and Neuendorff DA (1987) Effect of estrus synchronization with Synchro-Mate-B on serum luteinizing hormone, progesterone and conception rate in Brahman heifers Theriogenology 28 355-371

Rhodes FM, Fitzpatrick LA, De'ath G and Entwistle KW (1994) The effects of follicle wave numbers per oestrous cycle on the ovulatory follicle in Bos indicus heifers Theriogenology $\mathbf{4 1} 284$

Rhodes FM, Fitzpatrick LA, Entwistle KW and De'ath G (1995a) Sequential changes in ovarian follicular dynamics in Bos indicus heifers before and after nutritional anoestrus Journal of Reproduction and Fertility 104 41-49

Rhodes FM, Fitzpatrick LA, Entwistle KW and Kinder JE (1995b) Hormone concentrations in the caudal vena cava during the first ovarian follicular wave of the oestrous cycle in heifers Journal of Reproduction and Fertility 104 33-39

Roberson MS, Wolfe MW, Stumpf TT, Kittok RJ and Kinder JE (1989) Luteinizing hormone secretion and corpus luteum function in cows receiving two levels of progesterone Biology of Reproduction 41 997-1003

Sanchez T, Wehrman ME, Bergfeld EG, Peters KE, Kojima FN, Cupp AS, Mariscal V, Kittok RJ, Rasby RJ and Kinder JE (1993) Pregnancy rate is greater when the corpus luteum is present during the period of progestin treatment to synchronize estrus in cows and heifers Biology of Reproduction 49 1102-1107

Savio JD, Thatcher WW, Morris GR, Entwistle K, Drost M and Mattiacci MR (1993) Effects of induction of low plasma progesterone concentrations with a progesterone-releasing intravaginal device on follicular turnover and fertility in cattle Journal of Reproduction and Fertility 98 77.84

Scaramuzzi RJ, Adams NR, Baird DT, Campbell BK, Downing JA, Findlay JK, Henderson KM, Martin GB, McNatty KP, McNeilly AS and Tsonis CG (1993) A model for follicle selection and the determination of ovulation rate in the ewe Reproduction, Fertility and Development 5 459-478
Schmitt EJP, Drost M, Diaz T, Roomes C, Thatcher WW (1996) Effect of a gonadotropin-releasing hormone agonist on follicle recruitment and pregnancy rate in cattle Journal of Animal Science 74 154-161

Sirois J and Fortune JE (1990) Lengthening the bovine estrous cycle with low levels of exogenous progesterone: a model for studying ovarian follicular dominance Endocrinology 127 916-925

Spitzer JC, Jones DL, Miksch ED and Wiltbank JN (1978) Synchronization of estrus in beef cattle. III. Field trials in heifers using a norgestomet implant and injections of norgestomet and estradiol valerate Theriogenology 10 223-229

Stock AE and Fortune JE (1993) Ovarian follicular dominance in cattle: relationship between prolonged growth of the ovulatory follicle and endocrine parameters Endocrinology 132 1108-1114

Sunderland SJ, Crowe MA, Boland MP, Roche JF and Ireland JJ (1994) Selection, dominance and atresia of follicles during the oestrous cycle of heifers Journal of Reproduction and Fertility 101 547-555

Taylor C, Rajamahendran R and Walton JS (1993) Ovarian follicular dynamics and plasma luteinizing hormone concentrations in norgestomet-treated heifers Animal Reproduction Science 32 173-184

Taylor C, Manikkam M and Rajamahendran R (1994) Changes in ovarian follicular dynamics and luteinizing hormone profiles following different progestagen treatments in cattle Canadian Journal of Animal Science $\mathbf{7 4}$ 273-279

Walters DL, Schams D and Schallenberger E (1984) Pulsatile secretion of gonadotrophins, ovarian steroids and ovarian oxytocin during the luteal phase of the oestrous cycle in the cow Journal of Reproduction and Fertility 71 479-491

Wehrman ME, Roberson MS, Cupp AS, Kojima FN, Stumpf TT, Werth LA, Wolfe MW, Kittok RJ and Kinder JE (1993) Increasing exogenous progesterone during synchronization of estrus decreases endogenous $17 \beta$-estradiol and increases conception in cows Biology of Reproduction 49 214-220

Wright PJ and Malmo J (1992) Pharmacological manipulation of fertility Veterinary Clinics of North America: Food Animal Practice 8 57-89 